\title{
Creating a Community of Inquiry in Large- Enrollment Online Courses: An Exploratory Study on the Effect of Protocols within Online Discussions
}

\author{
Baiyun Chen \& Aimee deNoyelles \\ University of Central Florida \\ Kerry Patton \& Janet Zydney \\ University of Cincinnati
}

\begin{abstract}
It can be difficult to foster focused and effective communication in online discussions within large classes. Implementing protocols is a strategy that may help students communicate more effectively, facilitate their learning process, and improve the quality of their work within online discussions. In this exploratory research study, a protocol was developed and improved over two iterations in a very large undergraduate video-streaming business course $\left(N_{1}=412 ; N_{2}=450\right)$. The discussion instructions were consolidated and adjusted, and design elements such as a grading rubric, exemplary student samples, and due date reminders were added in the second iteration. There were higher perceptions of social, cognitive, and teaching presences in the second iteration, as well as significantly more group cognition within the discussion measured through a Community of Inquiry coding template. Findings suggest that protocols are a potentially useful strategy to manage online discussions in large classes.
\end{abstract}

Keywords: Community of Inquiry; large classes; online discussions; protocols

Chen, B., deNoyelles, A., Patton, K., \& Zydney, J. (2017). Creating a community of inquiry in large-enrollment online courses: An exploratory study on the effect of protocols within online discussions, Online Learning 21(1), 165-188. doi: 10.24059/ olj.v21i1.816

\section{Introduction}

Asynchronous discussions play an important role in online learning by providing a space for instructors and students to form a community, to engage in dialogue about the course content, and to co-construct knowledge (Gao, Zhang, \& Franklin, 2013). Because of the asynchronous nature of the discussions, participants have more time to think before responding, and the act of writing elicits the formation of new knowledge and ideas (Hew, Cheung \& Ng, 2010). In 
addition, discussion forums provide a permanent space for the participants to return to their original contributions, promoting reflection (Hew et al., 2010) and self-assessment (Gao et al., 2013).

Despite these affordances, it can be challenging to create and sustain focused, in-depth online discussions (Gao et al., 2013). In a literature review, Hew et al. (2010) identified several reasons why students do not fully participate in online discussions. Students will not fully participate when they do not see the purpose of the discussion, do not understand what to contribute, do not receive responses to their posting, and cannot make sense of the discussion due to the structure of the online forum. Therefore, online discussions must be structured in a way that clearly communicates their purpose and student expectations, encourages students to co-construct knowledge, and facilitates meaningful discussion. Past research has specifically identified the establishment of clear communication protocols and requirements for participating as vital for a successful discussion (Brannon \& Essex, 2001; Darabi, Liang, Survavanshi, \& Yurekli, 2013; Makitalo, Weinberger, Hakkinen, Jarvela, \& Fischer, 2005). An increasingly common constraint, however, is class size. While an optimal online class size is between 12 to 16 students for effective communication (Orellana, 2006; Tomei, 2006), online courses can sometimes hold hundreds of students. Even when sectioned into groups, it can be difficult for instructors to effectively facilitate online discussions due to logistical and grading issues.

The purpose of this paper is to explore the use of a discussion strategy called a protocol, which may potentially address the challenge of stimulating a productive discussion in a large online class. Protocols explicitly structure meaningful conversations with the purpose of stimulating student problem solving, reflection, and elicitation of support from others (McDonald, Zydney, Dichter, \& McDonald, 2012). Protocols establish a well-defined goal, clear roles, and set rules for interactions, and specific deadlines for posting. A notable example of a protocol is called the Tuning protocol (McDonald et al., 2012). The goal of this protocol is to improve ("tune") a particular work in progress. For this protocol, a participant shares the work in progress and has the opportunity to ask the others for relevant feedback. Others listen about the work in progress, and then ask clarifying and probing questions before supplying focused feedback. Finally, the participant reflects on the feedback and brainstorms ways to improve the work. This participant also listens and provides feedback to the others. In this way, protocols sharpen communication, enhance collective thinking, and build knowledge. The Tuning protocol exhibits the four core characteristics of a protocol that set it apart from other structured approaches (McDonald et al., 2012). First, all participants have a voice and play a designated role. Second, all participants engage in different and varied ways. Third, all participants have the dual roles of both creating as well as reading text. Finally, protocols foster trust since the norms are well established.

Protocols first started within face-to-face environments, but are now being explored in the online environment (McDonald et al., 2012). This study explored the use of protocols within online discussions in a large enrollment college course over a two-semester period. The explicit structure of a protocol may keep students in a large online class on track and focused on a goal, sustain the community, and eliminate the need for constant facilitation from the instructor. At the conclusion of the paper, specific enhancements that enable a protocol-based discussion to logistically work in a large online class are proposed. 


\section{Theoretical Background: Community of Inquiry}

The Community of Inquiry (CoI) framework has been used as one of the premier theories in the last two decades to conceptualize community in many online discussion research studies (see CoI website). The framework proposes three essential presences that contribute to a successful educational experience: social, cognitive, and teaching (Garrison, Anderson \& Archer, 2000; Garrison, Anderson, \& Archer, 2010). Social presence is the ability of learners to project themselves socially and emotionally, being perceived as "real" people in mediated communication (Garrison \& Arbaugh, 2007; Rourke, Anderson, Garrison \& Archer, 1999). Cognitive presence refers to the extent to which learners are able to construct and confirm meaning through sustained reflection and discourse (Garrison, Anderson \& Archer, 2001 \& Garrison \& Arbaugh, 2007). Finally, teaching presence is defined as the "design, facilitation, and direction of cognitive and social processes for the purpose of realizing personally meaningful and educationally worthwhile learning outcomes” (Anderson, Rourke, Garrison, \& Archer, 2001, p. 5).

Using these presences as a framework, an effective online discussion will encourage students to not only communicate on a social level but also engage in an academic conversation, while being purposely directed to achieve learning outcomes.

\section{Literature Review}

\section{Class Size}

There is no standardized definition of what constitutes a "large class." Maringe and Sing (2014) define large class size as "any class where the numbers of students pose both perceived and real challenges in the delivery of quality and equal learning opportunities to all students, in that classroom” (p. 763). The researchers adopt Maringe and Sing's definition for purposes of this paper and regard our target classes of over 400 students as large.

In the literature, class size was found to be a factor in students' interactions in online courses (Hewitt \& Brett, 2007; Orellana, 2006). The larger the class size is, the less likely students will actively engage in online activities (Rocca, 2010). Consequently, class size also negatively affects students' social engagement as well as creates information overload for students (Hewitt \& Brett, 2007). Past research has found that to maintain sufficient instructorstudent interactions, the ideal online class size was between 12 to 16 students to achieve the highest level of interactions (Orellana, 2006; Tomei, 2006). Due to student enrollment and administrative pressure, however, class sizes have continued to increase in American colleges in recent years. In this study's school, a regular general education course can be over one hundred students.

A search via Google Scholar and the Education Research Information Center (ERIC) database using the keywords "large class" and "online discussion" was conducted. Unfortunately, only a few journal articles were found on the topic of facilitating discussions in large online classes (see Yang, 2007). For large classes, it is recommended to section students into small groups to achieve high quality interactivity (Kim, 2013). Hew and Cheung (2011) found that as discussion group size increased up to 10 students, the level of knowledge construction also increased. Although prior research does identify strategies that are effective in eliciting knowledge in online discussions (see deNoyelles, Zydney, \& Chen, 2014), these studies 
often do not sample large enrollment online classes. Thus, more research is needed to determine how to meet the challenge instructors face in creating an effective online discussion activity in large undergraduate classes.

\section{Online Discussions and Protocol-based Discussions}

Research about online discussions in large classes is rare (Eyitayo, 2005). One study found that small group, online discussions can help students develop their critical thinking skills with skillful facilitation in a class of 133 students (Yang, 2007). The instructors divided the class into smaller groups and assigned five teaching assistants to be group facilitators who used Socratic questions. Unfortunately, most instructors who teach large classes are not equipped with multiple teaching assistants to assist with discussion facilitation. Given the constraints, is it still possible to use online discussions as a teaching/engagement strategy in large online classes?

In a review of literature, deNoyelles, Zydney \& Chen (2014) identified discussion strategies associated with higher levels of the CoI presences. One effective strategy noted was the use of protocols; however, empirical research on protocols in online discussions is scarce. One study that compared a protocol and a non-protocol online discussion in two small sections of a graduate course found that the three CoI presences exhibited by students were more evenly distributed in protocol-based discussions (Zydney, deNoyelles \& Seo, 2012). The protocol promoted more shared group cognition, rather than individual monologues. It also significantly increased students' opportunity to participate in the instructional design of the course, making teaching presence a shared responsibility between teachers and students. The findings indicated that the shared responsibility reduced the burden on the instructor for doing all the facilitation and enabled the instructor more time to diagnose misconceptions and inject knowledge when necessary.

Skillful facilitation is especially difficult in large online classes. Considering the benefits discovered from prior research on protocols, the researchers expected that protocol-based discussions could benefit large online classes where extensive instructor facilitation is not feasible. Therefore, our research focused on how to utilize one specific discussion strategy, the protocol, in order to improve students' perception and enactment of CoI in online discussions within large classes.

\section{Methodology}

This study examined what enhancements are needed to enable a protocol-based discussion to logistically work in a large class, and whether the enhancements made in the second design iteration of the protocol-based online discussions improved the CoI for a large enrollment course. Two research questions were posed:

(1) How did students in a large enrollment online course perceive the enhancements made to the protocol-based discussions?

(2) How did the enhancements made to the protocol-based discussions impact the elements that contribute to a Col? 


\section{The Context of the Study}

Online discussion protocols were developed and implemented in a large undergraduate business course (GEB3113) over two semesters (Iteration 1 and 2) in 2014, taught by the same instructor at the University of Central Florida. The course was classified as "video streaming," meaning that face-to-face attendance was optional, with the sessions being streamed to an online audience. Iteration 1 included 412 participants and Iteration 2 included 450. In both iterations, students regularly engaged in graded online discussions in groups of approximately 10 students (called "Bazinga circles”), resulting in at least 40 groups per semester.

Three protocol-based discussions were implemented in the course, each focused on written class assignments, with the goal of encouraging students to reflect and give meaningful feedback about each other's work. The protocol featured in this study was adapted from the Tuning protocol described in the introduction (McDonald et al., 2012), and was the first one offered in the course. The piece of work in question was the business model, which is essentially a description of an innovative business concept. Included in the business model are elements such as customer relationships, revenue streams, and key resources.

For both iterations, the online discussion protocol was divided into three basic parts:

- Part A: Students posted their written assignment (business model), and then asked group members to consider at least one aspect in which they desired constructive feedback.

- Part B: One week after Part A, students chose at least one person to whom to reply and provide feedback.

- Part C: One week after Part B, students reflected on the next steps for further developing their business model based on peer feedback.

- Once the discussion concluded, the students submitted the business model as a formal assignment for grading.

Based on feedback from the students and instructor, problem areas with the discussion were identified and enhancements were made to the online discussion protocol used, resulting in Iteration 2 of the discussion protocol (Appendix A).

Seven improvements were made after the first design iteration: 1) The discussion structure was simplified. In Iteration 1, Part A was in one discussion forum (i.e., a discussion board page), while Parts $\mathrm{B}$ and $\mathrm{C}$ were in a separate forum. As this resulted in confusion about how to interact with each other, in Iteration 2, Parts A and B were consolidated into one forum to encourage smoother peer feedback, with Part C (personal reflection) submitted as part of the final written Business Model assignment. 2) The feedback prompts were simplified. In Iteration 1 , students were told in part B to specify their peer feedback to be "warm" (describe what is working with the model), "cool" (consider aspects of work that need improvement) and/or "hard" (ask deeper questions that get at the larger aspects of the work). In an effort to simplify the instructions, in Iteration 2, this classification was omitted and students were only asked to provide feedback based on the first person's post. Instead of including complicated directions, the warm, cool, and hard feedback was modeled in example discussion posts. 3) To simplify the focus of the discussion, the discussion and the Business Model assignment instructions were 
separated. 4) Due dates for the multiple parts of the discussion were added to the course calendar in Iteration 2 to provide reminders to students. 5) Exemplary discussion samples were provided from past semesters in order to display good examples. 6) A rubric was added to explain how the discussion would be graded. 7) The point-value of the discussion went from 10 points to 30 points in order to encourage more careful work.

\section{Data Collection and Preparation}

With the approval from the Institutional Research Board, the research team collected two types of data, survey and discussion posts, over the two iterations (Table 1) in the spring and fall semesters of 2014. Based on the CoI framework, researchers created a survey instrument (Arbaugh et al., 2008) to measure the quality of online teaching and a coding template (Garrison et al., 2000) to analyze indicators of cognitive presence, social presence, and teaching presence in students' discussion activities. The researchers used these two instruments in our research to evaluate students' perceptions and discussions. At the end of each semester, a survey was distributed that asked students to assess the protocol discussions used in the course. This survey included two parts: a quantitative section that utilized the CoI instrument (Appendix B), which assessed students' perceived levels of social, cognitive and teaching presences with reference to the protocol-based discussions, and a qualitative section that included open-ended questions to assess students' feedback on the discussions. In addition to this survey, students' discussions were analyzed for the social, cognitive, and teaching presences. The triangulation of this data enabled us to examine CoI from two main perspectives: the closed-ended questions were directed mainly at the instructor role in fostering a CoI, the coding of the group discussions was focused on the students' contribution to $\mathrm{CoI}$ in the discussions, and the open-ended questions reflected both the instructor and student involvement.

Table 1

Data Source Types, Analyses, and Participant Number

\begin{tabular}{|c|c|c|c|}
\hline Data Source & Analysis & Iteration 1 & Iteration 2 \\
\hline Semester & & Spring & Fall \\
\hline Survey Closed-ended & $\begin{array}{l}\text { Descriptive \& } \\
\text { Independent } \\
\text { Samples T-Test }\end{array}$ & $N=394$ & $N=446$ \\
\hline Survey Open-ended I & Content Analysis & $N=394$ & $N=446$ \\
\hline Survey Open-ended II & Content Analysis & $N=394$ & $N=446$ \\
\hline Discussion posts & $\begin{array}{l}\text { Content Analysis } \\
\& \\
\text { Fisher's Exact Test }\end{array}$ & $\begin{array}{l}10 \text { (One selected } \\
\text { group) }\end{array}$ & $\begin{array}{l}11 \text { (One selected } \\
\text { group) }\end{array}$ \\
\hline
\end{tabular}




\section{Analyses}

For Research Question 1, the research team analyzed the open-ended survey results to evaluate students' perceptions towards the enhancements made to the protocol-based discussions. For Research Question 2, the researchers analyzed both the quantitative survey results and the discussion posts to assess if the enhancements made to the protocol-based discussions impacted the CoI elements.

Open-ended survey analysis. Students in both iterations were given open-ended questions as part of the course evaluation. In total, 840 students responded with comments on the protocol-based discussions. One open-ended question asked them to provide feedback about the discussions. In Iteration 2, an additional question asked students how the discussion contributed to their performance on the written assignment. A conventional content analysis was applied to the first open-ended survey question. Conventional content analysis emphasizes becoming immersed in the data so that new insights can emerge (Hsieh \& Shannon, 2005). For the initial analysis of the first open-ended survey question, one member of the research team who was unfamiliar with the course design of either iteration independently open-coded to reveal emerging themes, noting anything in relation to the main research questions. Examples of initial codes generated include group size, group composure, clarity of instructions, amount of feedback, type of feedback, and usefulness of feedback, among others. Codes were then organized into the following categories: instructions, group formation, improving learning, examples, and feedback. The second open-ended survey question was then analyzed, with the team member continuing with open coding, and filing them under the initial codes and categories when appropriate. Examples of emerging themes include clarity of instructions and purposeful group formation. Finally, a comparative qualitative analysis between the two iterations was performed on students' responses. The differences among the themes between the two iterations were then highlighted. In addition to allowing the themes to emerge from the data, the research team also discussed the themes in connection with the three presences of the CoI framework within the Discussion section (Merriam, 2001).

Quantitative survey analysis. For the quantitative survey results, frequencies were used to analyze information regarding the level of presences. Independent samples t-tests were conducted to investigate the differences in perceptions between two iterations.

Discussion post analysis. An in-depth analysis of the discussions of one group from Iteration 1 and 2 was conducted. The discussion posts were downloaded, cleared of student names and identifying information, and stored on a secure server as randomly numbered groups. To prepare for the coding process, one member of the research team with expertise in the modified CoI coding system (see Table 2) devised in an earlier study (Zydney et al., 2012) trained two other members. The main difference between the original CoI coding system developed by Garrison et al. (2000) and the modified one is that it separated the "individual and group categories within cognitive presence to distinguish between participants answering questions as a monologue unrelated to other participants' postings versus participants interactively discussing the topic with one another" (Zydney et al., 2012, p. 81). For this process, each complete thought was the unit of analysis and was coded for cognitive, social, and teaching presence as defined by this model. Each unit of analysis was coded for the highest level of cognitive presence and could have multiple social or teaching indicators. To establish the 
coding process among the research team, a practice group of posts was selected and coded by two members of the research team. The third observed to understand the process and provide input on any cases about which the original coders did not agree. A random group of posts from each iteration was then coded independently by two researchers who later met to resolve discrepancies. A total of 366 ratings was assigned with 47 discrepancies for an inter-rater reliability of $87 \%$. All discrepancies were resolved for a $100 \%$ agreement.

After the discussion posts were coded, frequencies and percentages for each category by individual and group presence were calculated to analyze the differences in the group between the two iterations. In addition, the Fisher's Exact test (2-sided) was used to identify statistically significant results. This nonparametric test was chosen because of the small sample size. Following this analysis, further qualitative investigations were done to identify differences between protocol iterations. Examples of student posts were used to illustrate any variances.

Table 2.

CoI Coding Template (adapted from Garrison et al. (2000))

\begin{tabular}{|c|c|c|c|}
\hline Elements & Categories & Indicators & Example \\
\hline \multirow{5}{*}{$\begin{array}{l}\text { Cognitive } \\
\text { Presence }\end{array}$} & Triggering Event & A new or related topic is raised & $\mathrm{NA}^{\mathrm{a}}$ \\
\hline & $\begin{array}{l}\text { Exploration - } \\
\text { Individual }\end{array}$ & $\begin{array}{l}\text { Ideas, experiences, and prior } \\
\text { knowledge are repeated and/or } \\
\text { described }\end{array}$ & $\begin{array}{l}\text { "Obstacles I am anticipating } \\
\text { include funding the business and } \\
\text { establishing brand awareness and } \\
\text { loyalty." }\end{array}$ \\
\hline & $\begin{array}{l}\text { Exploration - } \\
\text { Group }\end{array}$ & $\begin{array}{l}\text { Ideas are exchanged among the } \\
\text { group, questions are asked to } \\
\text { confirm understanding }\end{array}$ & $\begin{array}{l}\text { "I like your idea to make a } \\
\text { Bookstore/Cyber Cafe that would } \\
\text { sell college books under retail } \\
\text { value." }\end{array}$ \\
\hline & $\begin{array}{l}\text { Integration - } \\
\text { Individual }\end{array}$ & $\begin{array}{l}\text { Prior knowledge and/or } \\
\text { experience is related to the } \\
\text { text; texts are related to each } \\
\text { other }\end{array}$ & $\begin{array}{l}\text { "I’ve talked to many friends and } \\
\text { family members which has caused } \\
\text { me to want my product to be a } \\
\text { value based product instead of } \\
\text { cost driven." }\end{array}$ \\
\hline & $\begin{array}{l}\text { Integration - } \\
\text { Group }\end{array}$ & $\begin{array}{l}\text { Ideas of others are connected } \\
\text { and/or expanded upon; } \\
\text { counterpoints raised; } \\
\text { improvements are suggested }\end{array}$ & $\begin{array}{l}\text { "While I agree with his premise } \\
\text { that word of mouth advertising is } \\
\text { great, it's not the least bit practical } \\
\text { for a business that's just starting } \\
\text { out; you must advertise through } \\
\text { other mediums first to get your } \\
\text { name out there." }\end{array}$ \\
\hline
\end{tabular}


Resolution Individual

Resolution Group

Social Emotional

Presence Expression

Open
Communication

Group Cohesion

Teaching

Instructional

design and

organization
Applying ideas to personal future, theory to practice

Applying what has been discussed
"Many large groups have the pain of paying far too much for too many rooms to fit all of their members in... My hotel chain will solve these problems by... putting the large groups into larger rooms for far less cost to them.”

“The response I got from $\mathrm{X}$ completely turned my original idea around. At first, my plan was having the customers get picked up from home by a professional driver who takes them for a ride. This idea proved to be risky because it would be incredibly tricky to get an insurance company to cover injuries that can possibly occur on public roads. With having a closed course, I can stay within certain parameters to severely lessen liability on my business.”

"Feel free to give me a ring when and if you need any graphic design or photography work done, D, ha-ha."

"XX, I think the concept of bringing the gym to the customer is a great idea."

“I hope this helped a little!” community building, helping and supporting

Identify and prompt discussion topics 
$\begin{array}{ll}\begin{array}{l}\text { Facilitating } \\ \text { discourse }\end{array} & \begin{array}{l}\text { Asking others for feedback, } \\ \text { encouraging the direction of } \\ \text { the discussion }\end{array}\end{array}$

Direct instruction
Explain content in an authoritative way, provide support for claims, providing resources
"If anyone has any feedback or ideas they would like to share on reducing costs, I would greatly appreciate it!”

$\mathrm{NA}^{\mathrm{a}}$

${ }^{\mathrm{a}} \mathrm{NA}$ - not applicable because it did not show up in the groups' discussions.

\section{Results}

A number of themes developed for the first open-ended survey responses including the clarity of instructions, purposeful group formation, improving learning and gaining new perspectives, encouraging community and collaboration, providing examples and eliciting effective feedback. An overall comparison of open-ended responses between iterations yielded a variety of similarities and differences among the six themes.

Similar themes between iterations. Overall, responses across iterations were found to be similar for clarity of instructions, purposeful group formation, improving learning and gaining new perspectives and encouraging community and collaboration.

Clarity of instructions. The responses concerning the instructions and access to the discussions were overwhelmingly positive with almost all students reporting clear, easy-to-use instructions as one student illustrated, "The discussions were very accessible and easy to reply to other posts. I thought the instructions were spot on and I had no difficulties." A very small amount of the responses suggested a variety of changes. A few students commented that the instructions were too long, with one student suggesting that, "The instructions were too complex that it caused confusion... If the instructions were simplified then they would be easier to follow.” A few students suggested that it was initially unclear where or when to post responses, or the proper place was difficult to find among all the other groups. A small number of students also requested reminders of dates that responses were due, or suggested that some due dates were unclear. One student suggested that, "I believe the instructions could have been described in a way for it to be easier to understand along with the due dates."

Purposeful group formation. Many suggestions focused on group formation, however, the suggestions varied greatly. Some students wanted a larger group for more feedback, while others asked for smaller groups for more personal communication. For example, one student suggested that future discussions should include "larger Bazinga circles [discussion groups] to ensure more replies and comments being shared.” In contrast, another student suggested that, "maybe by making groups smaller you could improve this experience." Some students chose to focus on group composition by suggesting that groups include students of similar interests, while other suggestions asked for groups to include students of varied interest. To illustrate, one 
student wrote, "I would have liked Bazinga groups to be picked because of similarities in the field even if it fell down to just separating it into products and services. Or what the industry is."

Improving learning and gaining new perspectives. Students also reported that their performances on the class assignments were improved because the structured discussion allowed them to get multiple perspectives, iron out details, and identify problems. For example, one student commented that, "The structured discussions were very easy to understand and helped me learn more about my ideas from different perspectives." In addition, giving feedback to other students was reportedly helpful by providing peer examples to compare to their own work. Overall, students felt that the protocol discussion helped them receive a better grade on the final project. One student summarized this idea by writing, "I really liked the discussions. This helped wrap everything up that the research team had learned. The end discussions, which I felt I was very prepared for, was thanks to the Bazinga discussions.”

Encouraging community and collaboration. Finally, students reported that the group discussion made them feel better about their work and interacting with the class. One student reported that "the discussions gave me a feeling of belonging and collaborating with other students," while another commented that, "I was able to interact with my peers more than in any other online course I've taken." With class sizes in the 350-450 range, it is easy for students to feel disconnected, especially in an online setting. However, the protocol discussions may have helped students feel connected, with one student stating "I found the discussions helpful! They definitely helped me develop a sense of community within the class." The protocol discussions were also reported to increase collaboration. As one student wrote, "I thought the discussions were great and made me feel like I was actually a part of the class. Being in such large classes is tough and having a small group collaborations helped immensely.”

Different themes between iterations. Responses concerning provided examples and effective feedback were considerably different between groups.

Providing examples. Although the overall response to clarity of instructions was similar between iterations, one difference emerged. Students in both iterations consistently responded that instructions were clear and easy to follow. Additionally, the students in Iteration 2 often elaborated that the provided examples were helpful. One student suggested

The instructions were very clear and concise. I love that you guys give us clear instructions AND an example of what you are somewhat looking for. Makes working on the assignment a lot easier and is very reassuring to know I am on the right track.

Eliciting effective feedback. Responses concerning effective feedback were considerably different between groups. The students in Iteration 2 more often offered positive responses regarding effective feedback, while the students in Iteration 1 compiled more negative responses in this area. Feedback from students in Iteration 1 more often identified the negative aspects of feedback including lack of feedback, ineffective last-minute feedback, or feedback that was minimal. For example, a student from Iteration 1 responded that

I felt as though I didn't receive adequate feedback through the circle discussions, and I never met any of the members in my group. I posted several assignments and asked for 
feedback but didn't receive any. It was clear from the feedback that I did receive that some students did actually take the assignment seriously and attempt to provide me with a different perspective to aid me, but others were short and frankly quite useless.

Students in Iteration 2 more often responded that the feedback was helpful and provided insight. As one student from Iteration 2 responded, "By using feedback from my Bazinga group members I was better able to come up with and expand on my business concept after taking into account the various ideas and contributions that my group members gave me. Very helpful!”

Additional themes related to additional question for iteration 2. In Iteration 2, an additional question was added to the course survey to provide further insight into how the protocol-based discussions influenced the performance on the Business Model assignment. A number of additional themes developed including guiding student progress, utilizing peer examples, and revising and refining ideas.

Guiding student progress. Students felt that the protocol discussion helped them to keep pace with the course schedule and assignments. Students reported being forced to start assignments early, to understand material in order to be able to participate in discussions, and to keep up to date with responses. As a result, students had more time to reflect and modify their work before turning in the final copy. One student wrote, "The structured (protocol) discussions, like the Business Model assignment, helped me with time management. Since assignments were due first in the discussion it allowed me to schedule my time more efficiently."

Utilizing peer examples. In addition, students felt that the discussions allowed them to see examples of other student's work, and provided a basis to compare their own work. As one student suggested, "I loved the structured (protocol) discussions! It was great to see many examples of what my peers were doing, to help improve my own understanding of the assignement and better my performanace."

Revising and refining ideas. The students reported that the protocol discussions helped to improve performance by allowing them to revise and refine their ideas. The discussions allowed students to share their ideas, receive feedback from their peers, and adjust the assignments before submission. For example, a student responded

They helped me in a number of ways, but the most is when I was missing something or didn't go into detail about something, the people in my Bazinga group caught it and helped me score very high on these assignments. They would also tell me things like 'I love your idea but have you thought about adding this?' and with things like that it really helped me to refine my idea and made it stronger than I ever thought possible!

\section{Research Question 2: How Did the Enhancements Made to the Protocol-Based Discussions Impact the Elements that Contribute to a CoI?}

A summary of the quantitative survey results and the quantitative and qualitative analysis of the discussion posts indicate that the enhancements made to the protocol-based discussions positively influenced elements of the CoI. In particular, the cognitive presence among students was significantly higher in Iteration 2 than in Iteration 1. 
Summary of quantitative survey results. Exploratory analyses (Table 3) showed that for both iterations, all three presences of the CoI were perceived at high levels. However, students' perceptions of teaching, social, and cognitive presences were significantly higher in Iteration 2.

Table 3.

Means and Standard Deviations of the Three Presences in the Two Iterations

Iteration 1 (Spring 2014) Iteration 2 (Fall 2014)

\begin{tabular}{lccllll}
\hline & $N$ & Mean & Std. Deviation & $N$ & Mean & Std. Deviation \\
$\begin{array}{lcclll}\text { Teaching } \\
\begin{array}{l}\text { Presence } \\
\text { Social Presence }\end{array}\end{array}$ & 394 & 4.04 & 0.60 & 446 & 4.27 & 0.51 \\
$\begin{array}{l}\text { Cognitive } \\
\begin{array}{l}\text { Presence } \\
\hline\end{array}\end{array}$ & 394 & 3.79 & 0.72 & 446 & 4.10 & 0.63 \\
\hline
\end{tabular}

There were statistically significant differences in all three presences between the two iterations (Table 4). These results suggest that the improved discussion protocol in Iteration 2 did have an effect on students' perception of online community. Specifically, when the discussion protocol is enhanced, students perceived a higher sense of teaching presence, social presence and cognitive presence.

Table 4.

Mean Differences and T-Value of the Three Presences Between the Two Iterations

\begin{tabular}{lllll} 
& Mean Difference $t$ & $d f$ & Sig. (2-tailed) \\
\hline $\begin{array}{l}\text { Teaching } \\
\text { Presence }\end{array}$ & .23 & 6.05 & 770 & $<.001^{* * *}$ \\
$\begin{array}{l}\text { Social Presence } \\
\text { Cognitive }\end{array}$ & .31 & 6.60 & 788 & $<.001^{* * *}$ \\
$\begin{array}{l}\text { Presence } \\
\text { 33 }\end{array}$ & 6.79 & 773 & $<.001^{* * *}$ \\
\hline
\end{tabular}

Note: $* * * p<.001$.

Discussion post analysis. Overall, the students' discussions from Iteration 2 presented a higher frequency of social presence than the discussions from Iteration 1, as shown in Table 5. The frequencies and percentages of cognitive, social, and teaching presence in the discussions were similar between iterations. Further analysis was done to assess differences between iterations within each category. 
Table 5.

Overall Differences between Cognitive, Social, and Teaching Presence

\begin{tabular}{|c|c|c|c|c|c|c|}
\hline \multirow[t]{2}{*}{ Element } & \multirow[t]{2}{*}{$n$} & \multicolumn{2}{|l|}{ Iteration 1} & \multirow[t]{2}{*}{$n$} & \multicolumn{2}{|l|}{ Iteration 2} \\
\hline & & Frequency & $\%$ & & Frequency & $\%$ \\
\hline Cognitive & 10 & 48 & 62 & 9 & 49 & 55 \\
\hline Social & 10 & 21 & 27 & 9 & 31 & 35 \\
\hline Teaching & 10 & 8 & 11 & 9 & 9 & 10 \\
\hline Total & 10 & 77 & 100 & 9 & 89 & 100 \\
\hline
\end{tabular}

Cognitive presence. An examination of the instances of cognitive presence between iterations revealed a significantly higher rate of individual exploration in Iteration 1 in the discussions $(p=.03)$ as shown in Table 6 . In addition, this led to a significantly higher presence of total individual cognition for the students in Iteration $1(p=.03)$. Subsequently, the students in Iteration 2 produced a significantly higher rate of total group cognition $(p=.03)$ with higher frequencies achieved in all three categories. Overall, the students in Iteration 2 displayed a more even distribution between individual and group cognition.

A qualitative examination of the discussion posts revealed further differences among the groups. Posts to part A of the discussion, in which students presented their business models and asked for feedback were similar across iterations. However, responses to parts B (providing peer feedback) and C (reflection and improvement of the business model) were shorter and coded at a lower cognitive presence in Iteration 1. For example, a typical response by the students in Iteration 1 to part B of the assignment was "It all looks pretty solid to me \#4 good work."

While one of the shorter responses by a student in Iteration 2 was:

Hey \#7, love the idea!

Many people in your target market are going to be interested in the business you have to offer and are going to love the service you provide them. Many large parties don't like to be separated when having a good time in a hotel and hate to pay more just to get extra rooms. I like the idea of the unlimited access to entertainment in the lobby as well and the personal caterer.

Your strategic alliance will be key to your business to get up and get going. Your business is going to need key investors that are willing to work with you and believe in the work you're going to get done. Liability may be an issue as well because when you have a lot of people in one room it can tend to get a bit reckless and things may break in the room that were not your businesses fault. So make sure you have liability covered when people check in for your services.

In many cases, the responses of students from Iteration 1 to parts $B$ and $C$ of the assignment were 1 to 2 sentences that were coded with low cognitive presence or with none at all. However, the 
students in Iteration 2 more often responded in multiple paragraphs that were coded at various group levels.

Table 6

Differences in Categories within Cognitive Presence

\begin{tabular}{|c|c|c|c|c|c|}
\hline \multirow[t]{2}{*}{ Element } & \multicolumn{2}{|l|}{ Iteration 1} & \multicolumn{2}{|l|}{ Iteration 2} & \multirow[t]{2}{*}{$p$} \\
\hline & Frequency & $\%$ & Frequency & $\%$ & \\
\hline Triggering Event & 0 & 0 & 0 & 0 & 0 \\
\hline \multicolumn{6}{|l|}{ Individual } \\
\hline Exploration & 25 & 52 & 14 & 29 & $.03 *$ \\
\hline Integration & 7 & 15 & 5 & 10 & .55 \\
\hline Resolution & 3 & 6 & 5 & 10 & .71 \\
\hline Sub-total & 35 & 73 & 24 & 49 & $.03 *$ \\
\hline \multicolumn{6}{|l|}{ Group } \\
\hline Exploration & 6 & 10 & 9 & 18 & .58 \\
\hline Integration & 7 & 17 & 14 & 29 & .15 \\
\hline Resolution & 0 & 0 & 2 & 4 & .50 \\
\hline Sub-total & 13 & 27 & 25 & 51 & $.03^{*}$ \\
\hline Total & 48 & 100 & 49 & 100 & - \\
\hline
\end{tabular}

Note: $* p<.05$.

Social presence. There were no significant differences between iterations in terms of social presence (Table 7), although the students in Iteration 2 had a higher frequency of social presence. In each iteration, the social presence was largely focused in three areas: compliments, directing a comment to someone specific, and emotional expression. A qualitative difference among the iterations was that the students in Iteration 1 often expressed concern over doing the assignment correctly, while many of the students in Iteration 2 complimented fellow students' ideas as seen in the quote below.

Iteration 1:

\#3, everything looks great only thing I would say is check with the professor to make sure its [sic] ok to number them. I was a bit lost of this because I remember she said no bullets. Are numbers considered bullets? I don't even want to chance it myself. 
Iteration 2:

I value any input from my group members. Let me know what I need to work on.

Table 7

Differences in Categories within Social Presence

\begin{tabular}{lccccc} 
& Iteration 1 & \multicolumn{3}{c}{ Iteration 2} & $p$ \\
\cline { 2 - 5 } & Frequency & $\%$ & Frequency & $\%$ & \\
\cline { 2 - 5 } Emotional Expression & 3 & 14 & 4 & 13 & .72 \\
Open Communication & 17 & 81 & 25 & 81 & .18 \\
Group Cohesion & 1 & 5 & 2 & 6 & 1 \\
Total & 21 & 100 & 31 & 10 & - \\
\hline
\end{tabular}

Teaching presence. There were no significant differences between iterations in terms of teaching presence as seen in Table 8. In each iteration, the teaching presence was focused on facilitating discourse. This was primarily accomplished by prompting others to generate new ideas as a reflection on the business model. Posts were similar across iterations.

Table 8

Differences in Categories within Teaching Presence

\begin{tabular}{lccccc}
\hline Element & Iteration 1 & \multicolumn{3}{c}{ Iteration 2 } & $p$ \\
\hline & Frequency & $\%$ & Frequency & $\%$ \\
\cline { 2 - 5 } & 0 & 0 & 0 & 0 & - \\
$\begin{array}{l}\text { Instructional Design \& } \\
\text { Organization }\end{array}$ & 8 & 100 & 9 & 100 & 1 \\
Facilitating Discourse & 0 & 0 & 0 & 0 & - \\
Direct Instruction & 8 & 100 & 9 & 100 & - \\
Total & & & &
\end{tabular}

\section{Discussion}

The current study examined the use of discussion protocols in large classes to engage students and facilitate discussions. In the following section, the theoretical and practical implications of the research findings are discussed. 


\section{Community of Inquiry}

One unexplored area of research is the use of protocol-based discussions in large enrollment courses to improve students' perception of the CoI. After making several enhancements (e.g., simplifying the instructions, adding example posts, providing a rubric) in the second design iteration of protocol-based discussions, the research team noted changes associated with the cognitive presence, social presence, and teaching presence.

Cognitive presence. After the enhancements were made to the discussion-based protocols in Iteration 2, students perceived a significantly higher level of cognitive presence. This may be the result of the new perspectives gained from increased feedback received from peers. In closely examining one group's discussion posts from each iteration, the researchers also noted a statistically significantly higher level of group cognition in discussion posts in the second iteration. This increased group interaction may have resulted from the protocol-based discussions becoming more structured with clearer directions and expectations set for what students were supposed to do. This result corroborates an earlier study that found that group cognition increased with a protocol-based discussion over non-protocol-based discussion (Zydney et al., 2012). It may be that increasing the structure of protocol-based discussions further improves upon group cognition; however, additional research would be needed to confirm this idea.

Social presence. Similar to what was seen with cognitive presence, the enhancements to the discussion protocols in Iteration 2 significantly improved students' perception of social presence in the discussions. Although students' ratings of social presence improved in the second iteration, other data sources showed similarities between the two iterations. For example, the analysis of the open-ended survey results revealed a similar theme of community and collaboration across both iterations, with students noting feelings of community and belonging. Moreover, the analysis of the small group discussions revealed no difference pertaining to social presence between the two iterations. This lack of statistical significance may be the result of the fact that both design iterations included smaller sub-group discussions that enabled students to interact with one another more. (Kim, 2013).

Teaching presence. Students' perception of teaching presence also significantly improved after enhancements were made to the protocol-based discussions in Iteration 2. This difference may be the result of the increased peer feedback noted by students who received the second iteration of the discussion protocols. Although students' ratings of teaching presence improved in Iteration 2, examination of the group discussions revealed no statistical difference between levels of teaching presence in students' posts, regardless of which iteration they received. This was illustrated by similar numbers of posts from students helping to facilitate discussion by encouraging feedback from one another. This lack of statistical significance in levels of teaching presence in the discussion posts may be the result of the fact that, regardless of the enhancements made, the protocol itself is designed to enable students to facilitate themselves in the discussion. This result was also noted in an earlier study that found that the "protocol helped the students facilitate themselves and empowered them to design the discussion" (Zydney et al., 2012, p. 85). 


\section{Practical Implications}

The findings of this study generate important implications for facilitating meaningful online discussions in large classes. Most importantly, the findings of this study suggest that implementing protocol-based discussions is a plausible teaching strategy in classes with large enrollments. Students could achieve effective communication and interactions within small groups of approximately 10 members in large classes, and the optimal group size is still an interesting area for future research. Students in this study enjoyed the small communities, felt a sense of connection to classmates, and benefited from peer learning that would not be achievable otherwise in large-size classes. Protocols help keep the large community on the same page; everyone knows what is expected, including the instructor.

It is essential to closely attend to the "protocol" nature of the discussion prompt. For larger classes, especially, the prompt needs to be explicit, with due dates being clear, and examples given. As the research team found, the second design iteration resulted in higher perceptions of community and more even distribution of the presences. Being explicit is extremely important in very large classes to prevent mass confusion. It is important to explain the purpose of the protocol, what to contribute, how to provide feedback to peers, and the timeline. In addition, the very nature of the discussion set-up is important. Including the original post and peer feedback in one discussion forum enables smooth communication between peers; this communication was less frequent in the first iteration when parts A and B were separated.

It appears that, in large undergraduate classes, students prefer scaffolding with authentic examples and simplified, but clear instruction. Although both cohorts felt that they received clear instruction for the discussion activity, Iteration 2 was particularly successful due to added features such as examples, grading rubrics, and due date reminders. It was surprising that students in Iteration 2 were more satisfied with the quality of the feedback, given that more detailed direction on how to give peer feedback was provided to students in Iteration 1 . The design enhancements in the second iteration resulted in fewer concerns over the "correctness" of the assignment and reassured the students. There was also less concern about when the discussion parts were due. This finding suggests a "less is more" instructional design approach; instead of providing a large amount of clarified instruction, it may be advantageous to offer the most concise instruction possible along with an example.

It was also surprising that even after adding due date reminders in the course calendar, there was still feedback from students in Iteration 2 about needing more reminders of the multiple due dates for the protocol-based discussion. This points to the need for more student support in the use of the learning management system (LMS). Students need to not only be able to submit assignments and check grades, but also to skillfully leverage the features of the LMS (such as the course calendar) to support their own learning. Therefore, student training emerges as an issue for further pursuit. 


\section{Limitations and Future Research}

There are several limitations to this study. One major limitation is the convenience sample selection. Even though this study had a large sample size over two iterations, the data only included undergraduate students in one business class at one southeastern university in the United States. In future studies, the research team will include classes of various disciplines and school environments to assess whether the current findings would generalize to varied contexts or samples. Moreover, the researchers only randomly selected one group from each iteration for discussion analyses, which limits the sample size of these quantitative analyses. More studentgroups should be analyzed to see if the results are consistent in future studies.

In addition, future research will use controlled experimental studies to measure the effect of protocol-based discussion on students' overall learning. Our study results showed a statistically significant group cognition but the effect was confounded by other factors, such as students' prior knowledge and the increase in assigned grade to protocol-based discussions in Iteration 2. The research team plans to implement pre- and post-examinations for future studies to control for individual differences between classes. Also, the effectiveness of modeling in protocol-based discussion is one that warrants further research.

In summary, this study provides some evidence that the protocol-based discussion activity can engage students and enhance their cognitive presence in large classes. More research is needed in large online classes to further examine the effects of the discussion strategies on students' learning. The researchers hope that this research will be useful to educational practitioners and researchers as they continue to investigate and build a knowledge base of teaching strategies for large online classes, especially engagement strategies to build personal learning communities without having to place heavy logistical burdens on instructors.

\section{References}

Anderson, T., Liam, R., Garrison, D. R., \& Archer, W. (2001). Assessing teaching presence in a computer conferencing context. Journal of the Asynchronous Learning Network, 5(2). Retrieved from http://www.sloan-c.org/publications/jaln/v5n2/index.asp

Anderson, T., Rourke, L., Garrison, D. R., \& Archer, W. (2001). Assessing teaching presence in a computer conferencing environment. Journal of Asynchronous Learning Networks, 5 (2).

Arbaugh, J. B., Cleveland-Innes, M., Diaz, S. R., Garrison, D. R., Ice, P., Richardson, J. C., \& Swan, K. P. (2008). Developing a community of inquiry instrument: Testing a measure of the community of inquiry framework Using a multi-institutional sample. Internet and Higher Education, 11(3-4), 133-136. doi: 10.1016/j.iheduc.2008.06.003

Brannon, R., \& Essex, C. (2001). Synchronous and asynchronous communication tools in distance education. TechTrends, 45(1), 36-42. 
Darabi, A., Liang, X., Suryavanshi, R., \& Yurekli, H. (2013). Effectiveness of online discussion strategies: A meta-analysis. American Journal of Distance Education, 27(4), 228-241. Doi: 10.1080/08923647.2013.837651

deNoyelles, A., Zydney, J.M. \& Chen, B. (2014). Best practices for creating a community through online discussions. Journal of Online Learning and Teaching, 10(1). Retrieved from http://jolt.merlot.org/vol10no1/denoyelles_0314.pdf

Eyitayo, O. (2005). Experimenting e-Learning with a large class. International Journal of Education and Development Using ICT, 1(3). Retrieved from http://ijedict.dec.uwi.edu/viewarticle.php?id=109\&layout=html

Gao, F., Zhang, T., \& Franklin, T. (2013). Designing asynchronous online discussion environments: Recent progress and possible future directions. British Journal of Educational Technology, 44(3), 469-483. doi: 10.1111/j.1467-8535.2012.01330.x

Garrison, D. R., Anderson, T., \& Archer, W. (2010). The first decade of the community of inquiry framework: A retrospective. The Internet and Higher Education, 13(1-2), 5-9. doi: 10.1016/j.iheduc.2009.10.003

Garrison, D. R., \& Arbaugh, J. B. (2007). Researching the community of inquiry framework: Review, issues, and future directions. The Internet and Higher Education, 10(3), 157172. doi: 10.1016/j.iheduc.2007.04.001

Garrison, D. R., Anderson, T., \& Archer, W. (2000). Critical inquiry in a text-based environment: Computer conferencing in higher education. The Internet and Higher Education, 2(2-3), 87-105. Doi: 10.1016/S1096-7516(00)00016-6

Garrison, D. R., Anderson, T., \& Archer, W. (2001). Critical thinking, cognitive presence, and computer conferencing in distance education. American Journal of Distance Education, 15(1).

Hew, K.F., \& Cheung, W.S. (2011). Higher-level knowledge construction in asynchronous online discussions: An analysis of group size, duration of online discussion, and student facilitation techniques. Instructional Science, 39, 303-319. Retrieved from: http://www.jstor.org/stable/23882804

Hew, K.F., Cheung, W.S., \& Ng, C.S. (2010). Student contribution in asynchronous online discussion: A review of the research and empirical exploration. Instructional Science, 38, 571-606. doi: [add here]

Hewitt, J., \& Brett, C. (2007). The relationship between class size and online activity patterns in asynchronous computer conferencing environments. Computers \& Education, 49(4), 1258-1271. doi: 10.1016/j.compedu.2006.02.001 
Hsieh, H., \& Shannon, S.E. (2005). Three approaches to qualitative content analysis. Qualitative Health Research, 15(9), 1277-1288.

Kim, J. (2013). Influence of group size on students’ participation in online discussion forums. Computers \& Education, 62, 123-129. doi: 10.1016/j.compedu.2012.10.025

Makitalo, K., Weinberger, A., Hakkinen, P., Jarvela, S., \& Fischer, F. (2005). Epistemic cooperation scripts in online learning environments: fostering learning by reducing uncertainty in discourse? Computers in Human Behavior, 21, 603-622.

Maringe, F., \& Sing, N. (2014). Teaching large classes in an increasingly internationalising higher education environment: Pedagogical, quality and equity issues. Higher Education, 67(6), 761-782. doi:1007/s10734-013-9710-0

McDonald, J.P., Zydney, J.M., Dichter, A., \& McDonald, B. (2012). Going online with protocols: New tools for teaching and learning. NY: Teachers College Press.

Merriam, S. B. (2001). Qualitative research and case study applications in education. (2nd ed.). San Francisco: Jossey-Bass Publishers.

Orellana, A. (2006). Class size and interaction in online courses. The Quarterly Review of Distance Education, 7(3), 229-248. Retrieved from http://wps.prenhall.com/wps/media/objects/4512/4621309/Survey_Online_Class_Size.pd $\underline{\mathrm{f}}$

Rocca, K.A. (2010). Student participation in the college classroom: An extended multidisciplinary literature review. Communication Education, 59(2), 185-213. doi: 10.1080/03634520903505936

Rourke, L., Anderson, T. Garrison, D. R., \& Archer, W. (1999). Assessing social presence in asynchronous, text-based computer conferencing. Journal of Distance Education, 14(3), 51-70.

Tomei, L. (2004). The impact of online teaching on faculty load: Computing the ideal class size for online courses. International Journal of Instructional Technology \& Distance Learning, 1(1). Retrieved from http://itdl.org/journal/jan_04/article04.htm

Yang, Y.-T. C. (2007). A catalyst for teaching critical thinking in a large university class in Taiwan: asynchronous online discussions with the facilitation of teaching assistants. Educational Technology Research and Development, 56(3), 241-264. doi: 10.1007/s11423-007-9054-5

Zydney, J. M., deNoyelles, A., \& Seo, K. K.-J. (2012). Creating a community of inquiry in online environments: An exploratory study on the effect of a protocol on interactions within asynchronous discussions. Computers \& Education, 58(1), 77-87. doi:10.1016/j.compedu.2011.07.009 
Acknowledgements. The research team is grateful to Ms. Kathie Holland, the course instructor, for giving us permission to conduct our research and continuously working with us on improving the online discussion activities.

\section{Appendix A: Iteration 2 Protocol}

For this group discussion posting, I would like you to use a specific structure called a "Tuning” protocol. The Tuning process allows for reflection and meaningful feedback about your Business Model, and will likely result in your creating a better business model, and earning a better grade, too. This structure assumes that you want to improve your business model, and that your Bazinga Circle members will deliver thoughtful and substantive feedback. Think of it like tuning up a car or an orchestra. Your communal goal is to help each other make A's on this assignment, so do this early in the week so you can use their feedback to improve your success on your assignment.

There are three parts to this discussion structure: Parts A, B, and C.

\section{Part A: Due Week 8}

Begin your post with the words "PART A". Begin with a one- or two-sentence description of your business to remind everyone what your concept is. Share the elements of your emerging Business Model. Then ask your Circle members to review your submission and give you feedback about something specific in your Business Model you believe could be improved. (For example, perhaps you want their feedback on your Revenue Streams or on Validation and Pivoting.)

For Example: (example provided here by the instructor)

\section{Part B: Due Week 10}

Choose one group member's Business Model and provide feedback to him or her. Each member should give and get feedback from at least one member, so reply to someone who hasn't received any feedback yet. Your communal goal is to help each other make A's on this assignment.

Begin your post with the words "Part B". Then provide feedback that will help your group member to improve their submission. 
For Example: (example provided here by the instructor)

Part C (to be submitted with the Business Model assignment): Reflect on what happened as a result of this structured discussion. What ideas did your group members provide that helped you to improve your Business Model? Who had the best one; why was it better than the others?

\section{Appendix B: Survey Instrument}

\section{Teaching Presence}

Design \& Organization

1. The instructor clearly communicated important course topics.

2. The instructor clearly communicated important course goals.

3. The instructor provided clear instructions on how to participate in course learning activities.

4. The instructor clearly communicated important due dates/time frames for learning activities.

Facilitation

5. The instructor was helpful in identifying areas of agreement and disagreement on course topics that helped me to learn.

6. The instructor was helpful in guiding the class towards understanding course topics in a way that helped me clarify my thinking.

7. The instructor helped to keep course participants engaged and participating in productive dialogue.

8. The instructor helped keep the course participants on task in a way that helped me to learn.

9. The instructor encouraged course participants to explore new concepts in this course.

10. Instructor actions reinforced the development of a sense of community among course participants.

Direct Instruction

11. The instructor helped to focus discussion on relevant issues in a way that helped me to learn.

12. The instructor provided feedback that helped me understand my strengths and weaknesses.

13. The instructor provided feedback in a timely fashion.

\section{Social Presence}

Affective expression

14. Getting to know other course participants gave me a sense of belonging in the course.

15. I was able to form distinct impressions of some course participants.

16. Online or web-based communication is an excellent medium for social interaction.

Open communication

17. I felt comfortable conversing through the online medium.

18. I felt comfortable participating in the course discussions.

19. I felt comfortable interacting with other course participants.

Group cohesion

20. I felt comfortable disagreeing with other course participants while still maintaining a sense of trust.

21. I felt that my point of view was acknowledged by other course participants.

22. Online discussions help me to develop a sense of collaboration. 


\section{Cognitive Presence}

Triggering event

23. Problems posed increased my interest in course issues.

24. Course activities piqued my curiosity.

25. I felt motivated to explore content related questions.

\section{Exploration}

26. I utilized a variety of information sources to explore problems posed in this course.

27. Brainstorming and finding relevant information helped me resolve content related questions.

28. Online discussions were valuable in helping me appreciate different perspectives.

Integration

29. Combining new information helped me answer questions raised in course activities.

30. Learning activities helped me construct explanations/solutions.

31. Reflection on course content and discussions helped me understand fundamental concepts in this class.

Resolution

32. I can describe ways to test and apply the knowledge created in this course.

33. I have developed solutions to course problems that can be applied in practice.

34. I can apply the knowledge created in this course to my work or other non-class related activities.

5 point Likert-type scale

1 = strongly disagree, 2 = disagree, 3 = neutral, 4 = agree, $5=$ strongly agree 